Sains Malaysiana 50(10)(2021): 3067-3075

http://doi.org/10.17576/jsm-2021-5010-19

\title{
The Impact of Different Types of Orthodontic Appliances and Its Location in Producing CT Scan Artefacts
}

(Impak Jenis Peralatan Ortodontik yang Berbeza dan Lokasinya dalam Penghasilan Artefak Imbasan CT)

\author{
Mahmud Mohammed, Norma AB. Rahman* \& Ahmad Hadif Zaidin SAMSUdin
}

\begin{abstract}
Fixed orthodontic appliances can produce metal artefacts in CT images which may degrade the diagnostic image quality. The study aimed to evaluate the artefacts based on the types and location of the metallic and non-metallic orthodontic brackets. This is an in-vitro cross-sectional study. Four different types of orthodontic brackets (stainless steel, titanium, monocrystalline, and polycrystalline ceramic bracket) were bonded consecutively in four different locations of the cadaveric skull. All scans were performed by a single operator using the same CT machine followed by a standard scanning protocol. Artefact intensity for all data sets was quantified by calculating the standard deviation (SD) of the grey values within the dataset by following a standard method. The One-way ANOVA Bonferroni test was used for the data analysis. The mean artefact score of the stainless steel bracket was significantly $(\mathrm{p}<0.001)$ high in comparison with other types of the orthodontic brackets. Besides, the mean artefact score was significantly $(\mathrm{p}=0.002)$ low when orthodontic brackets were placed unilaterally. Stainless steel brackets produced a significant amount of noise in CT images which can degrade the diagnostic image quality. Thus, the polycrystalline ceramic bracket can be a better alternative of stainless steel brackets for patient need frequent CT scan.
\end{abstract}

Keywords: Artefact; computed tomography; orthodontic bracket

ABSTRAK

Peralatan ortodontik tetap boleh menghasilkan artefak logam pada imej CT yang boleh merendahkan kualiti imej diagnostik. Tujuan kajian ini adalah untuk menilai artefak berdasarkan komposisi dan lokasi pendakap metalik dan bukan metalik. Empat jenis peralatan ortodontik tetap (keluli tahan karat, titanium, polikristalin dan mono-kristalin) dilekatkan secara berturut-turut di empat lokasi berbeza pada tengkorak kadaver. Kesemua imbasan dilakukan oleh seorang operator menggunakan mesin CT yang sama diikuti oleh protokol piawai pengimbasan. Keamatan artefak untuk kesemua set data diukur dengan menghitung sisihan piawai dengan mengikuti kaedah piawai. Ujian ANOVA Bonferroni sehala digunakan untuk menganalisis data. Skor artefak peralatan ortodontik tetap keluli tahan karat secara signifikannya adalah tinggi $(p<0.001)$ berbanding dengan peralatan ortodontik tetap ortodontik lain. Tambahan lagi, purata skor artefak adalah rendah secara signifikan $(p=0.002)$ apabila peralatan ortodontik tetap dilekatkan secara unilateral. Peralatan ortodontik tetap keluli tahan karat menghasilkan sejumlah artefak yang signifikan dalam imej CT yang boleh merendahkan kualiti diagnostik imej. Dengan demikian, pendakap seramik polikristalin boleh menjadi alternatif kepada peralatan ortodontik tetap keluli tahan karat untuk pesakit yang memerlukan imbasan CT.

Kata kunci: Artefak; pendakap ortodontik; tomografi berkomputer

\section{INTRODUCTION}

Computed tomography (CT) scan is an important clinical diagnostic tool to diagnose both soft and hard anatomical structures of the human body. CT scan is also normally used during emergency clinical conditions such as intracranial lesion due to a head injury (Gunzinger et al. 2014). CT scan has now involved as an important and valuable imaging tool for clinical assessments and investigations for a wide range of pathologies. Moreover, advanced cross-sectional imaging technique of CT scan can be used in dentomaxillofacial imaging to solve complex diagnostic and treatment-planning problems, such as those encountered in craniofacial fractures, endosseous dental implant planning, and orthodontic treatment planning (Miracle \& Mukherji 2009). 
In CT imaging, metal artefact is a common phenomenon. This type of artefact can be caused by high attenuation of metal objects in the field of views such as dental restorations, orthodontic brackets, implants, surgical plates, and pins (Chindasombatjaroen et al. 2011). This is because the metal objects are highly attenuated by the x-ray beam resulting in incorrect high attenuation values of objects behind the metal. The severity of the metal artefact depends on several factors such as shape, size, composition and location of the metal objects in the image, sequence parameter and sequence types (Klinke et al. 2012). Metal artefacts are more pronounced with high atomic number metals, such as iron, stainless steel or platinum; whereas, low atomic number metals, such as nickel and titanium show less pronounced artefacts (Boas \& Fleischmann 2012; Prell et al. 2010). Previously, many studies have been done to assess the artefact generated from the metal used in dentistry such as orthodontic brackets, dental implant and metallic restoration (Chindasombatjaroen et al. 2011; Hirschinger et al. 2015; Hokamp et al. 2020; Pauwels et al. 2013).

Fixed orthodontic treatments are considered timeconsuming as it may take months to years to be completed. Within this period, the patient may involve in medical emergencies such as road traffic accident (RTA), cerebrovascular accident (CVA) or trauma which requires a craniofacial $\mathrm{CT}$ scan for diagnostic purpose. The artefacts produced by the orthodontic appliances during the craniofacial CT scan may cause misinterpretation of the fracture or lesion leading to misdiagnosis.

The fixed orthodontic appliance is the bracket type device made of metal, ceramic or plastic which are directly or indirectly bonded to the teeth surface with an adhesive. The main purpose of bracket placement is to engage the archwire into the slot and this archwire allows constant pressure which over time will move teeth into the desired positions (Graber et al. 2016). According to the literature survey, there is a very limited study on the impact of different types of orthodontic brackets in craniofacial anatomical CT scan. Previous studies only quantified the artefact from metal and polycrystalline ceramic brackets in the CT image (Hirschinger et al. 2015; Sanders et al. 2007). There was no study done to assess the effect of monocrystalline ceramic bracket to the image quality of $\mathrm{CT}$ scan according to the location of bracket neither was there any impact over different location and with other bracket systems. Therefore, the purpose of this study was to evaluate the artefacts produced by different types of the fixed orthodontic bracket (metallic or non-metallic) in craniofacial CT images based on their composition and location.

\section{Methods AND MATERIALS}

This was an in-vitro cross-sectional study involving a human cadaveric skull and a single unit conventional CT scan machine (TOSHIBA CGGT-032A). An adult cadaveric skull head which was selected has all teeth present in both jaws. Scanning of the cadaveric skull without any orthodontic brackets was done as a control image which later termed as the reference scan. The cadaveric skull head was placed in a standardized position by the help of the laser light of the CT machine and a custom-made box before the scanning. A total of four types of the brackets (Table 1) were bonded consecutively to the cadaveric skull teeth (right second premolar to left second premolar) following the manufacture bonding and debonding procedure. A standard scanning and reconstruction protocol were used for all the scanning (matrix size 512512 field of view 200200, slice thickness $1 \mathrm{~mm}$, peak tube voltage $120 \mathrm{kV}$, tube current $225 \mathrm{mAs}$ and pitch $0.75 \mathrm{~s}$ ).

\section{ETHICAL APPROVAL}

The study was approved by the Human Research and Ethics Committee of the Universiti Sains Malaysia (USM/JEpem/17070352). Written permission was obtained from the Anatomy library of USM. All research was performed following relevant guidelines and regulations.

\section{IMAGE ANALYSIS \\ Image registration}

Signal loss and signal amplification within all datasets were visualized by using the freely available open-source software (ImageJ version 1.52e Wayne Rasband, National Institute of Health. USA). After visualizing all the datasets, only metal artefact affected by axial slices were accounted by a radiologist for image analysis. From each scan, sixteen axial slices were selected for artefact evaluation according to the visibility of orthodontic appliances. After that, all sixteen axial slices were manually registered with the corresponding control slices with ImageJ software (Figures $1 \& 2$ ).

\section{PLACEMENT OF THE REGION OF INTEREST}

A fixed region of interest (ROI) (364254 pixels) was placed in the axial view of all synchronised axial slices (Figure 3). This ROIs encompasses the entire insert, including the teeth, bone and orthodontic appliance itself. The location of the ROIs was determined by the radiologist. The location of the ROIs was constant for all of the datasets which were determined by the anatomical 
landmark. Four different anatomical landmarks were selected for placing the ROIs which made ROIs constant in all axial slices. Every time before placing the ROI, the anatomical landmark needs to be merged with the given point of the ROI. There are total eight-point in the ROI (Figure 3), from there the top middle point (point $\mathrm{A}_{1}$; $\mathrm{x}, \mathrm{y}=252,22$ ) and the lower middle point (point $\mathrm{A}_{2} ; \mathrm{x}, \mathrm{y}$ $=252,258$ ) need to be placed between the lower central incisor. The right and left middle point (point $\mathrm{B}_{1} ; \mathrm{x}, \mathrm{y}=$ 96,140 and point $\left.B_{2} ; x, y=408,140\right)$ need to be placed parallel to the mesial canal of right second molars.

\section{REMOVAL OF BONE TEETH AND APPLIANCE FROM THE SELECTED IMAGES}

Artefacts intensity within the CT images were measured by using the same open-source software ImageJ. Removal of the teeth, bone and orthodontic brackets from the ROIs were done by manual thresholding (Figure 4). As it was seen before, there is no appropriate standardized segmentation method for removing the metal and bone from the ROIs (Pauwels et al. 2013). For this reason, the maximum and minimum threshold for all images were selected manually for excluding the bone, teeth, and metal which is constant. The maximum threshold for all of the data was $+100 \mathrm{HU}$ to exclude the bone, teeth and the appliance from the ROIs and the minimum lower limit threshold for all the data was -3072 HU. The Grey values which lied within the red threshold areas of ROIs were only accounted for image analysis (Figure 4). This manual thresholding depends on the maximum and minimum grey value of the metal and bones.

TABLE 1. Types of metallic and non-metallic brackets

\begin{tabular}{lll}
\hline Bracket material & Trade name & Manufacturer \\
\hline Monocrystalline & Zetta Monocrystalline & Natural Orthodontic product \\
Polycrystalline & Advanced Zeemas & \\
Stainless steel & C ceramic bracket & mEm Dental Technology \\
Titanium & EPS metal bracket & mEm Dental Technology \\
\hline
\end{tabular}
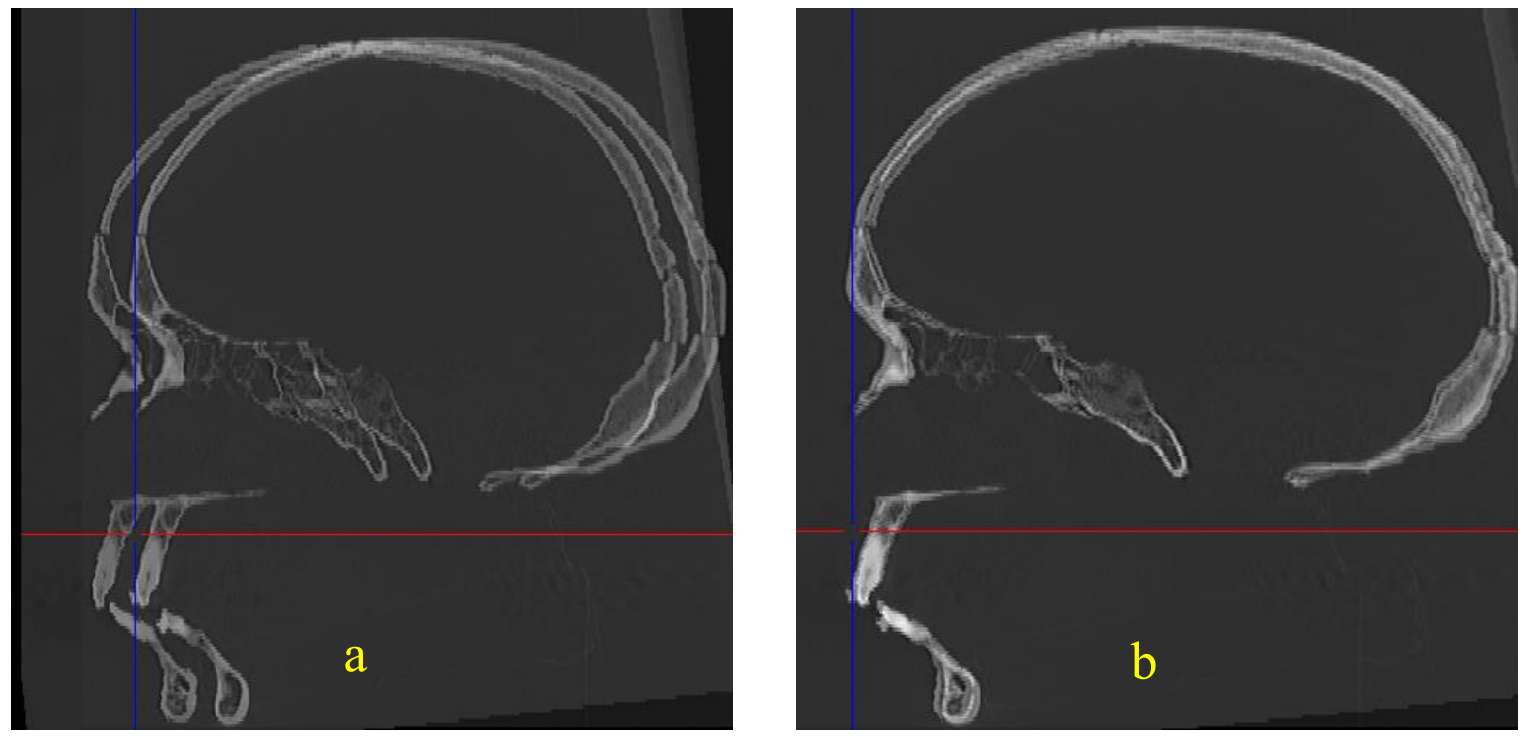

FIGURE 1. Manual alignment and synchronization of the stack with control stack (a) Before synchronization of the stack, and (b) After synchronization of the stack 


\section{CALCULATION OF THE MAXIMUM STANDARD DEVIATION (SD)}

The ImageJ software automatically measured the mean, standard deviation (SD), maximum and minimum grey values within the fixed ROIs of the axial slices. Besides, mean, standard deviation (SD), maximum and minimum grey values for control slices were also calculated.

$$
\max S D=\sqrt[2]{\frac{(\max \text { gray values }- \text { mean })^{2}+(\min \text { gray values }- \text { mean })^{2}}{(n-1)}}
$$
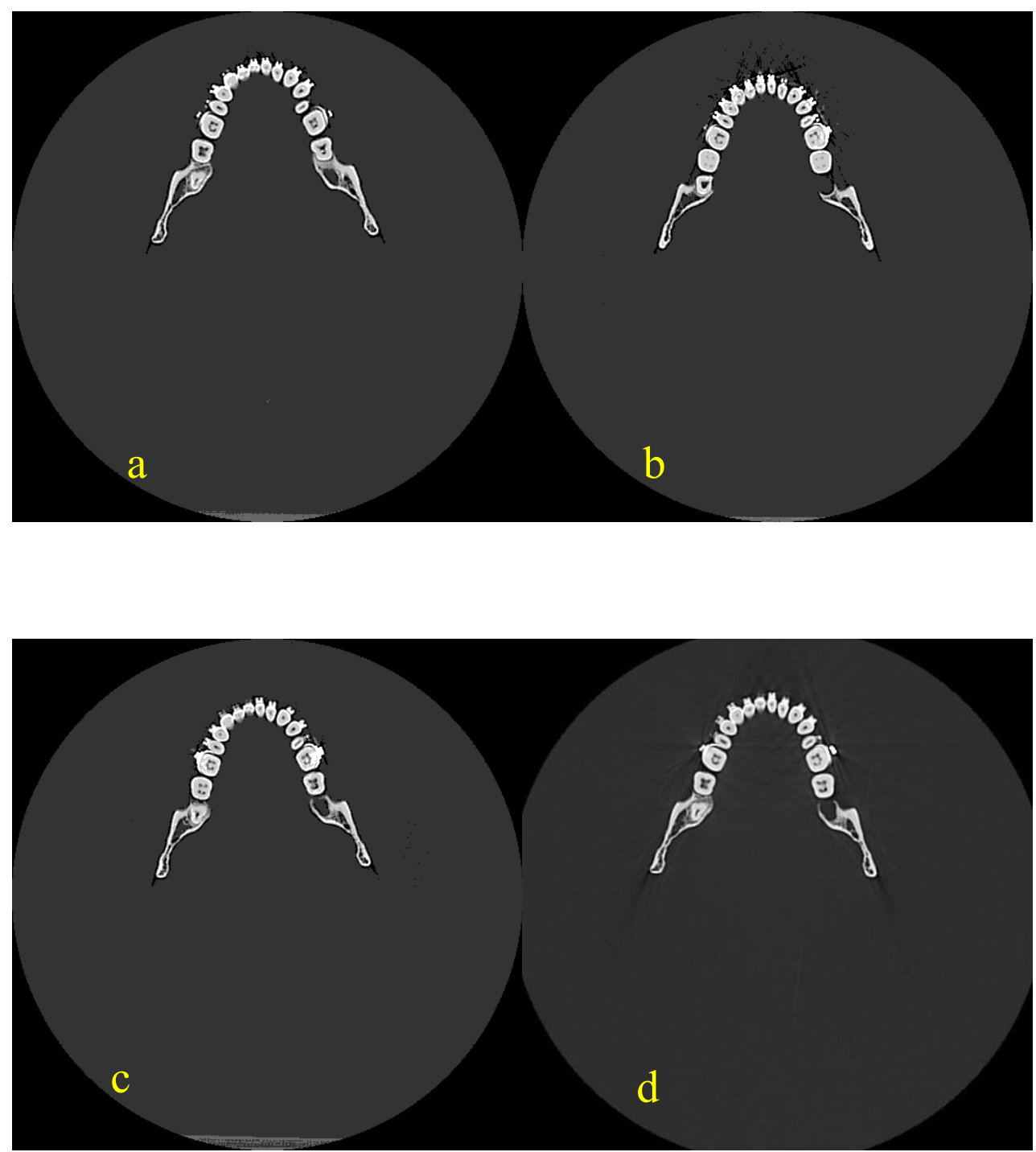

FIGURE 2. A set of synchronized $1 \mathrm{~mm}$ thick axial images derived from a corresponding set of four standardized secondary reconstructions a) Stainless steel brackets, b) Titanium brackets, c) Monocrystalline ceramic brackets, and d) Polycrystalline ceramic brackets 


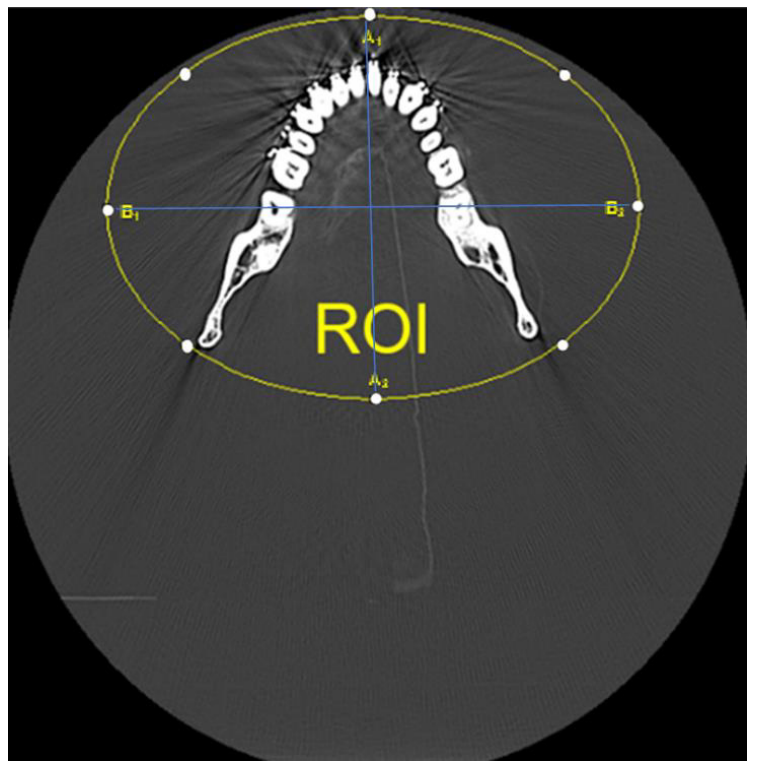

FIGURE 3. ROI within metal artefact affected slice with stainless steel orthodontic bracket where $\mathrm{A}_{1}, \mathrm{~A}_{2}, \mathrm{~B}_{1}$ and $\mathrm{B}_{2}$ indicating the anatomical landmark

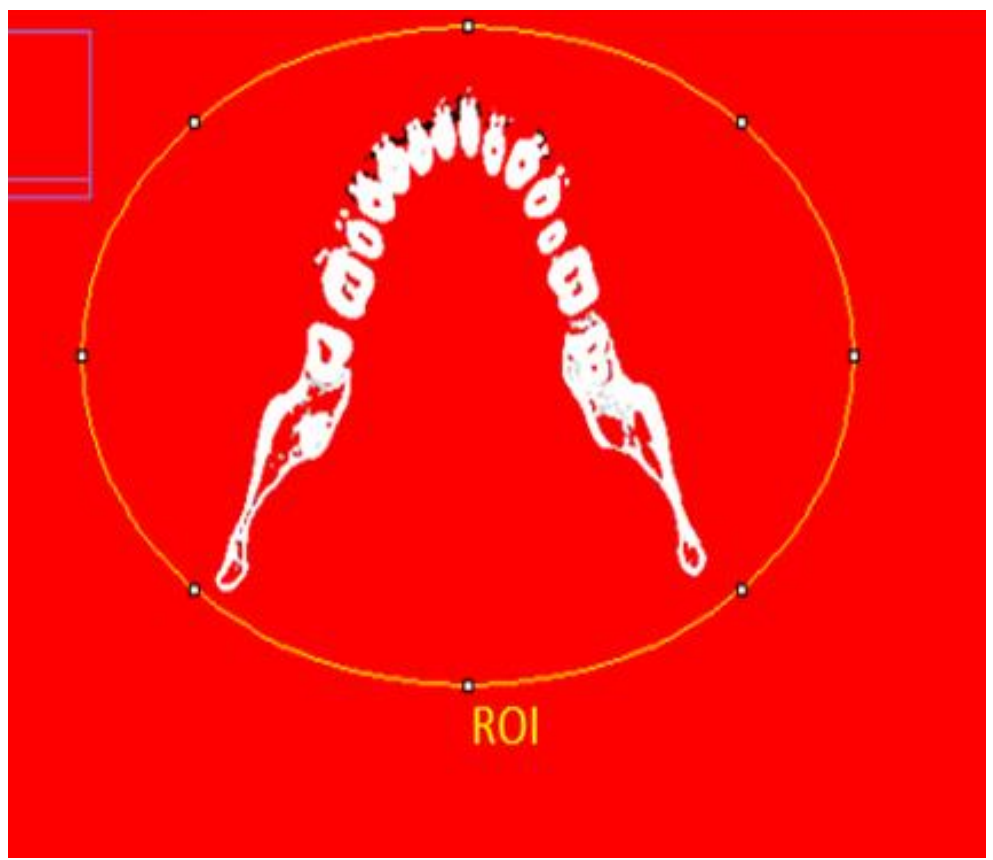

FIGURE 4. Removal of bone, teeth, and brackets within the ROI by manual thresholding and measuring the mean and standard deviation of grey values within the threshold ROI with ImageJ software 


\section{CONVERSION OF THE STANDARD DEVIATION (SD) TO THE PERCENTAGE OF ITS MAXIMUM STANDARD DEVIATION (MAX SD)}

After calculating the standard deviation and maximum standard deviation within all datasets, the actual SD within all datasets were divided by this maximum SD and multiplying with 100 and this will represent the actual SD in a percentage of its maximum SD. A higher percentage indicated more pronounced artefact score. The percentage of the maximum standard deviation estimated the overall extent of darkening and brightening streak artefact within the ROIs of the stacks (Pauwels et al. 2013).

\section{RELIABILITY TEST}

One observer conducted each measurement twice at an interval of two weeks to consider the variability (Arshad et al. 2017). In this current study, there was a two-week interval between the first and second observation to eliminate memory bias. Therefore, for each data, the measurements were carefully repeated four times by two observers to achieve an acceptable consistency. The values of all four measurements were used for the reliability analysis.

\section{STATISTICAL ANALYSIS}

Statistical analyses were performed by using the Statistical Package for the Social Sciences (SPSS) software version 24.0 (IBM, Armonk, NY, USA). The level of significance was considered, $p<0.05$. The normality of data distribution was confirmed by the descriptive histogram.

One-way analysis of variance (ANOVA) was done to assess the statistical difference in the mean values of artefact scores (percentage of maximum SD) between different types and locations of the orthodontic bracket. This was then followed by the Bonferroni test for pairwise comparisons to detect the groups that are significantly different.

\section{RESULT}

There was a significant mean difference $(p<0.001)$ of artefact scores between the different bracket groups. The post-hoc multiple pairwise comparisons using Bonferroni test (Table 2) showed that there was a significant mean difference of artefact score between stainless steel bracket and titanium bracket, stainless steel bracket and polycrystalline bracket, stainless steel bracket and monocrystalline bracket, titanium bracket and polycrystalline bracket; $p<0.05$, but there was no significant difference between monocrystalline and titanium bracket, monocrystalline and polycrystalline bracket; $p>0.05$ (Table 2). In addition, a significant difference $(p=0.002)$ of artefact scores also noted between the different bracket group based on their location. Later on, the Bonferroni test showed that there was a significant mean difference of artefact score between unilateral and both jaw, unilateral and maxillary bracket group, $p<0.05$ but no significant difference between both jaw and maxilla, both jaw and mandible, maxilla and mandible (Table 3). Moreover, the artefact scores exhibited excellent intra and inter-rater reliability because the ICC values of the intra and inter-rater reliability tests were more than 0.9 .

TABLE 2. Multiple comparisons of the mean artefact scores

between different types of orthodontic bracket

\begin{tabular}{|c|c|c|c|c|c|}
\hline \multirow{2}{*}{ Groups } & \multirow[b]{2}{*}{ Groups } & \multirow[b]{2}{*}{ Mean difference } & \multirow[b]{2}{*}{$p$-value } & \multicolumn{2}{|c|}{$95 \%$ confidence interval } \\
\hline & & & & $\begin{array}{l}\text { Lower } \\
\text { bound }\end{array}$ & Upper bound \\
\hline Stainless Steel & Monocrystalline & 0.668 & $<0.001^{*}$ & 0.358 & 0.977 \\
\hline Stainless Steel & Titanium & 0.362 & $0.014^{*}$ & 0.052 & 0.672 \\
\hline Stainless Steel & Polycrystalline & 0.921 & $<0.001^{*}$ & 0.611 & 1.230 \\
\hline Monocrystalline & Titanium & -0.305 & 0.056 & -0.615 & 0.004 \\
\hline Monocrystalline & Polycrystalline & 0.253 & 0.178 & -0.057 & 0.563 \\
\hline Titanium & Polycrystalline & 0.558 & $<0.001^{*}$ & 0.249 & 0.868 \\
\hline
\end{tabular}

* The mean difference is significant at the 0.05 level 
TABLE 3. Multiple comparisons of the mean artefact scores between the orthodontic bracket based on their location

\begin{tabular}{|c|c|c|c|c|c|}
\hline \multirow{2}{*}{ Groups } & \multirow{2}{*}{ Groups } & \multirow{2}{*}{ Mean difference } & \multirow{2}{*}{$p$-value } & \multicolumn{2}{|c|}{95 confidence interval } \\
\hline & & & & Lower bound & Upper bound \\
\hline Both Jaw & Maxilla & -0.083 & 1.000 & -0.582 & 0.416 \\
\hline Both Jaw & Mandible & 0.300 & 0.635 & -1.988 & 0.799 \\
\hline Both Jaw & Unilateral & 0.588 & $0.012 *$ & 0.089 & 1.088 \\
\hline Maxilla & Mandible & 0.384 & 0.242 & -0.116 & 0.883 \\
\hline Maxilla & Unilateral & 0.672 & $0.003^{*}$ & 0.173 & 1.171 \\
\hline Mandible & Unilateral & 0.288 & 0.721 & -0.210 & 0.787 \\
\hline
\end{tabular}

*The mean difference is significant at the 0.05 level

\section{DISCUSSION}

Artefact intensities within the CT images were quantified according to the method described by Pauwel et al. (2013). According to the method, artefact intensity was evaluated by comparing the standard deviation (SD) of grey values, with a higher value representing more pronounced artefacts and vice versa. SD being a function of variance, those SD values would reflect artefact intensities because larger variance within the region of interest (ROI) indicated more artefact-induced nosiness. Later on, the SD values were converted into the percentage of their maximum SD to make the data comparable with the study mentioned in the literature (Pauwels et al. 2013).

In this current study, artefact evaluation was carried out over a complete set of four different types of the orthodontic bracket (the right second premolar to the left second premolar) in combination with stainless steel bands. Previously, few studies dealt with the artefact behaviour from different types of the orthodontic bracket in conventional CT scan. In the previous study, Hirschinger et al. (2015) reported that titanium brackets produce a higher artefact in conventional CT images in comparison with stainless steel brackets. However, our findings are not incongruent with the result of that study. This is because of the difference in the scanning protocol. In this current study, a standard scanning protocol was used for all the scanning where the tube current was $225 \mathrm{mAs}$ which was higher compared to the tube current used in the previous study $(80 \mathrm{mAs})$. In another study, Pauwel et al. (2013) showed that a lower tube current produced a higher artefact in titanium alloy. As in this current study, we used a higher tube current for all the scanning, the artefact from titanium bracket was comparatively lower. On the other hand, a similar trend of a result was observed in one previous study (Sanders et al. 2007). Sanders et al. (2007) evaluated the artefacts from different types of the orthodontic bracket in conebeam CT machine. In that study, the researchers used a complete set (the right second premolar to the left second premolar) of four different groups (stainless steel, titanium, ceramic and plastic) of orthodontic brackets. The result of that study showed a similar pattern of a result, similar to the present study. The researchers found that stainless steel brackets produced a significantly higher artefacts in all three conditions. Although the result showed a similar output to the present study, the result cannot be compared entirely because of a variation in artefact measuring method. In the previous study, the artefact was quantified in a different method which was according to the variation in the mean of the greyscale values. Whereas in this present study, the artefact was quantified according to the variation in the standard deviation (SD) of grey values. In addition, a conventional CT machine with a standard protocol was used for all the scanning to conduct this current study. However, in the previous study, the researchers used a cone beam CT machine for scanning of the cadaveric skull with different bracket groups.

Furthermore, Queiroz et al. (2018) evaluated artefacts from different dental alloy. The outcome of that study mentioned that metal with higher atomic 
number and higher density produced larger artefact than metal with a low atomic number. The atomic number of irons is 26 which is the main component of the stainless steel bracket. On the other hand, the atomic number for titanium is 22 which is lower than the atomic number of irons. The atomic number theory about metal artefact given by Queiroz et al. (2018) supports the result of the current study. Furthermore, there have been a few more studies conducted to assess the artefact from stainless steel and titanium in conventional $\mathrm{CT}$. The result of the previous studies mentioned that stainless steel produced significantly higher artefact compared to titanium (Filli et al. 2015). These shreds of evidence of the previous studies support the result of this current study.

Previously, no study was found in the literature that evaluated the artefact from the monocrystalline orthodontic bracket. Artefact score in the monocrystalline orthodontic bracket is only significantly $(\mathrm{P}<0.05)$ lower than the stainless bracket. Previous studies only quantified the artefact in ceramic and plastic brackets (Sanders et al. 2007). Previously, the researchers found no significant difference between the overall property of monocrystalline and polycrystalline ceramic brackets rather than the optical clarity. The monocrystalline brackets exhibit an equal force, bonding strength, fracture resistance property and frictional resistant like polycrystalline ceramic brackets but monocrystalline ceramic brackets are more translucent than polycrystalline ceramic brackets.

Comprehensive research has been done previously to evaluate the artefact in $\mathrm{CT}$ images according to the variation in metal location (Huang et al. 2015) although the researchers used a unilateral and bilateral dental implant for evaluating artefacts according to their locations. In this current study, metal artefact in a cadaveric skull was measured and compared according to the variation in the location of the orthodontic bracket (maxilla, mandible, both jaws, or unilateral side of both jaws) in combination with the stainless steel band in craniofacial CT images. The current study result showed that orthodontics brackets produced less artefact when they are placed unilaterally. A similar trend of the result was also noticed in one previous study. In the study, the artefact intensity was significantly lower when a metallic implant was placed unilaterally in comparison to bilateral implant placement (Huang et al. 2015). The findings of the previous study cannot be correlated entirely with the result of the present study as there is a variation in the CT machine and material. Although the result of the previous study cannot be correlated entirely with the recent study, the current study supports the findings of the previous study.

\section{CONCLUSION}

In conclusion, a difference in artefact intensity was observed depending on the types and location of the orthodontic bracket. Stainless steel bracket produced significantly higher artefact compared to other types of the orthodontic bracket. Besides, the orthodontic bracket produced fewer artefacts when the bracket was placed unilaterally in comparison to the other locations.

\section{CLINICAL IMPLICATIONS AND RECOMMENDATIONS}

To improve the diagnostic image quality, the result of this study suggests the use of polycrystalline ceramic bracket instead of the metallic orthodontic bracket for the medically compromised patient who needs frequent craniofacial CT scan for diagnosis and follow-up purposes. In addition, a high tube current should be used when scanning a patient with titanium bracket to reduce the artefact intensity. When there is a unilateral lesion or unilateral fracture, removal of the brackets on the same side of the lesion may improve the diagnostic image quality for better interpretation and diagnosis. The authors declare no competing interests.

\section{REFERENCES}

Arshad, A.I., Alam, M.K. \& Khamis, M.F. 2017. Assessment of complete unilateral cleft lip and palate treatment outcome using EUROCRAN index and associated factors. International Journal of Pediatric Otorhinolaryngology 100: 91-95.

Boas, F.E. \& Fleischmann, D. 2012. CT artifacts: Causes and reduction techniques. Imaging in Medicine 4(2): 229-240.

Chindasombatjaroen, J., Kakimoto, N., Murakami, S., Maeda, Y. \& Furukawa, S. 2011. Quantitative analysis of metallic artifacts caused by dental metals: Comparison of cone-beam and multi-detector row CT scanners. Oral Radiology 27(2): 114-120.

Filli, L., Luechinger, R., Frauenfelder, T., Beck, S., Guggenberger, R., Farshad-Amacker, N. \& Andreisek, G. 2015. Metalinduced artifacts in computed tomography and magnetic resonance imaging: Comparison of a biodegradable magnesium alloy versus titanium and stainless steel controls. Skeletal Radiology 44(6): 849-856.

Graber, L.W., Vanarsdall, R.L., Vig, K.W. \& Huang, G.J. 2016. Orthodontics-e-book: Current Principles and Techniques. New York: Elsevier Health Sciences.

Gunzinger, J.M., Delso, G., Boss, A., Porto, M., Davison, H., von Schulthess, G.K., Huellner, M., Stolzmann, P., Veit-Haibach, P. \& Burger, I.A. 2014. Metal artifact reduction in patients 
with dental implants using multispectral three-dimensional data acquisition for hybrid PET/MRI. EJNMMI Physics 1(1): 1-14.

Hirschinger, V., Hanke, S., Hirschfelder, U. \& Hofmann, E. 2015. Artifacts in orthodontic bracket systems in conebeam computed tomography and multislice computed tomography. Journal of Orofacial Orthopedics 76(2): 152-163.

Hokamp, N.G., Eck, B., Siedek, F., Dos Santos, D.P., Holz, J.A., Maintz, D. \& Haneder, S. 2020. Quantification of metal artifacts in computed tomography: Methodological considerations. Quantitative Imaging in Medicine and Surgery 10(5): 1033.

Huang, J.Y., Kerns, J.R., Nute, J.L., Liu, X., Balter, P.A., Stingo, F.C., Followill, D.S., Mirkovic, D., Howell, R.M. \& Kry, S.F. 2015. An evaluation of three commercially available metal artifact reduction methods for CT imaging. Physics in Medicine \& Biology 60(3): 1047.

Klinke, T., Daboul, A., Maron, J., Gredes, T., Puls, R., Jaghsi, A. \& Biffar, R. 2012. Artifacts in magnetic resonance imaging and computed tomography caused by dental materials. PLoS ONE 7(2): e31766.

Miracle, A. \& Mukherji, S. 2009. Conebeam CT of the head and neck, part 2: Clinical applications. American Journal of Neuroradiology 30(7): 1285-1292.

Pauwels, R., Stamatakis, H., Bosmans, H., Bogaerts, R., Jacobs, R., Horner, K. \& Tsiklakis, K. 2013. Quantification of metal artifacts on cone beam computed tomography images. Clinical Oral Implants Research 24(A100): 94-99.

Prell, D., Kyriakou, Y., Kachelrie, M. \& Kalender, W.A. 2010. Reducing metal artifacts in computed tomography caused by hip endoprostheses using a physics-based approach. Investigative Radiology 45(11): 747-754.
Queiroz, P.M., Oliveira, M.L., Groppo, F.C., Haiter-Neto, F. \& Freitas, D.Q. 2018. Evaluation of metal artefact reduction in cone-beam computed tomography images of different dental materials. Clinical Oral Investigations 22(1): 419-423.

Sanders, M., Hoyjberg, C., Chu, C., Leggitt, V. \& Kim, J. 2007. Common orthodontic appliances cause artifacts that degrade the diagnostic quality of CBCT images. Journal of the California Dental Association 35(12): 850-857.

Mahmud Mohammed

Conservative Dentistry \& Endodontics

Delta Medical College \& Maxillofacial Radiologist

ODC Healthcare, Dhaka

Bangladesh

Norma Ab. Rahman*

Orthodontic Unit, School of Dental Sciences

Universiti Sains Malaysia, Health Campus

16150 Kota Bharu, Kelantan Darul Naim

Malaysia

Ahmad Hadif Zaidin Samsudin

Radiology Department

School of Medical Sciences

Universiti Sains Malaysia, Health Campus

16150 Kota Bharu, Kelantan Darul Naim

Malaysia

*Corresponding author; email: drnorma@usm.my

Received: 19 March 2020

Accepted: 10 February 2021 